Artigo recebido em:

24.02.2019

Aprovado em:

14.07.2020

Ana Taís Martins

Professora do Programa de Pós-Graduação em Comunicação e do Departamento de Comunicação da Universidade Federal do Rio Grande do Sul. Doutora em Ciências da Comunicação pela ECA/USP com pós-doutorado em Filosofia da Imagem pela Université de Lyon III.

E-mail: anataismartins@ icloud.com
Estudos em Jornalismo e Mídia Vol. 17 № 2

Julho a Dezembro de 2020 ISSNe 1984-6924

\section{Desafios do ensino do fotojornalismo na cultura digital}

Ana Taís Martins

\section{Resumo}

Este trabalho descreve mudanças no processo de ensino-aprendizagem de fotojornalismo a partir da experiência docente numa universidade pública brasileira nos últimos 14 anos, cobrindo desde a transição das técnicas analógicas para a tecnologia digital até a consolidação da tecnologia digital. Os achados dessa experiência são interpretados sob a luz das teorias em torno da cultura visual, problematizando-se essas questões sobre as coerções ao imaginário introduzidas pelo entrecruzamento entre novas tecnologias de produção de imagens e rotinas do fotojornalismo. Apresentam-se a título ilustrativo algumas imagens produzidas recentemente no âmbito das atividades práticas das disciplinas de fotojornalismo. Conclui-se que o ensino do fotojornalismo traz constantes desafios técnicos, mas sobretudo éticos, com a complexificação cada vez maior dos conceitos de verdade e autoria num contexto de cultura digital.

Palavras-chave: Ensino. Fotojornalismo. Cultura visual.

\section{Challenges of teaching photojournalism in digital culture}

\begin{abstract}
This article describes changes in the teaching-learning process of photojournalism from the teaching experience in a Brazilian public university in the last 14 years, covering from the transition from analog to digital techniques to the consolidation of digital technology. The findings of this experience are interpreted in the light of the theories surrounding visual culture, problematizing these questions about the coercion to the imaginary introduced by the intertwining of new image production technologies and photojournalism routines. Some images recently produced within the practical activities of the photojournalism disciplines are presented as illustrations. It is concluded that the teaching of photojournalism brings constant technical challenges, but above all ethical, with the increasing complexity of the concepts of truth and authorship in a context of digital culture.
\end{abstract}

Key words: Teaching. Photojournalism. Visual culture. 


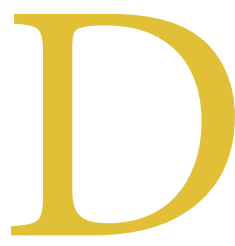

o ponto de vista tecnológico, o jornalismo tem se reconfigurado rapidamente e o fotojornalismo acompanha essas mudanças duplamente: a generalização das práticas com multiplataformas e o surgimento incessante de novos modelos de câmeras com mais recursos técnicos nos desafiam sem cessar. Isso já bastaria para fazer aflorar a angústia em relação à necessidade de constante atualização, mas a inovação que as últimas décadas trouxeram para a fotografia só pode ser comparável ao "Aperte o botão, nós fazemos o resto" da Kodak no final do século XIX. Assim como a introdução da câmera portátil com recursos automáticos, a fotografia em dispositivos móveis conectados à internet modificou profundamente os modos de fazer e de circular da fotografia e, inevitavelmente, do fotojornalismo.

A transição da fotografia analógica para a fotografia digital acompanhou e se fez acompanhar de uma reconfiguração dramática da cultura visual, que se tornou decididamente protagonista nas comunicações interpessoais digitais. $\mathrm{O}$ mesmo salto tecnológico que barateou e praticamente tornou universal a produção fotográfica - a impressão de onipresença dos telefones celulares dotados de dispositivo fotográfico é confirmada com números ${ }^{2}$ - não só trouxe modificações expressivas às práticas profissionais fotojornalísticas, como sobretudo transformou a cultura visual dos estudantes que ingressam nos cursos de Jornalismo e, mais cedo ou mais tarde, serão apresentados ao fotojornalismo.

No início dos anos 1990, a chegada da fotografia digital foi acompanhada, num primeiro momento, de discursos sobre o fim da fotografia e sobre o fim do regime da verdade. Mitchell (apud GUNTHERT, 2015) afirmou mesmo que a fotografia digital é tão diferente da fotografia quanto esta é da pintura. Esses discursos foram rapidamente rebatidos com argumentos que sinalizavam a inconsistência de definir a fotografia por seu suporte material:

Não há um meio, um conjunto de procedimentos e práticas singularmente fotográficas, passível de dotar as imagens de significados comuns [...] Seriam essas duas circunstâncias [imagens constituídas a partir de um aparelho fotossensivel e dependeram da existência de algo diante desse aparelho] suficientes para circunscrever o universo destas imagens de modo a dotá-las de uma marca única? (FATORELLI, 2005, p. 85).

Também a suscetibilidade da fotografia analógica às manipulações não resiste às argumentações que colocam em perspectiva essa característica da fotografia em geral, como observa ironicamente Fontcuberta:

Toda fotografia é uma ficção que se apresenta como verdadeira. Contra o que nos inculcaram, contra o que costumamos pensar, a fotografia mente sempre, mente por instinto, mente porque sua natureza não the permite fazer outra coisa. Contudo, o importante não é essa mentira inevitável, mas como o fotógrafo a utiliza, a que propósitos serve. O importante, em suma, é o controle exercido pelo fotógrafo para impor um sentido ético à sua mentira. O bom fotógrafo é o que mente bem a verdade (FONTCUBERTA, 2010, posição 129)

No entanto, a fotografia digital não se livrou de outras acusações, como a da concorrência dos amadores no fotojornalismo que, pelo exercício do "jornalismo cidadão" através das internet, trouxe a inquietação a respeito da degradação do jornalismo em geral até pelo menos o início dos anos 2010, segundo Gunthert (2015).

$\mathrm{O}$ autor francês observa que a passagem do analógico ao digital não trouxe à fotografia uma grande revolução nas imagens, com os profissionais se abstendo das potencialidades da fotografia digital até pelo menos 2010: "Na virada dos anos 2010, a revolução da imagem conectada ainda é percebida com desdém pelos fotógrafos e com desconfiança pelas indústrias, que não tinham pressa em integrar as capacidades comunicativas às ferramentas de registro clássicas", diz Gunthert (2015, p. 13, tradução minha). A inovação realmente transformadora veio da telefonia móvel que se tornou o espaço pioneiro das novas práticas visuais. A ampliação do acesso à fotografia digital e sua integração com as tecnologias da comunicação permitiu aos
${ }^{1}$ O presente trabalho foi realizado com apoio da Coordenação de Aperfeiçoamento de Pessoal de Nível Superior Brasil (CAPES). Uma versão preliminar desse texto foi publicada nos anais do $42^{\circ}$ Congresso Brasileiro de Ciências da Comunicação.

${ }^{2} J a ́$ desde pelo menos 2018, o Brasil tem mais de um telefone celular conectado por habitante, segundo pesquisa da Fundação Getúlio Vargas divulgada pelo jornal O Estado de São Paulo. Disponível em https://link. estadao.com.br/noticias/ geral,brasil-ja-tem-mais-de-um-smartphone-ativo-por-habitante-diz-estudo-da-fgv,70002275238. Acesso em: 5 mai. 2019. 
usuários produzir e enviar fotos para o seu círculo social, seja através da comunicação interpessoal seja através das redes sociais. Os modos de se perceber e de se produzir imagem são agora objeto de experiência de um grande público e não apenas dos fotógrafos e dos críticos. Em que pese isso não tornar cada usuário um fotógrafo profissional, traz uma espécie de educação popular para a imagem, o que impacta profundamente a cultura visual.

\section{Da prática ao ensino}

Sousa escrevia, em 2004 (p. 216), que "[...] a imagem digital é, em parte, vista como ética e deontologicamente transgressora ou perto da transgressão". De fato, a discussão sobre as potencialidades manipulatórias da fotografia digital pautava mais do que qualquer outra as reflexões sobre o fotojornalismo nesses anos. Foi nessa época, em 2006, que iniciei minhas atividades docentes em fotografia no ensino público superior na Universidade Federal do Rio Grande do Sul. Ensinar fotojornalismo trouxe desafios específicos sobre a conjunção entre teoria e prática. Nessa conjunção, entrou em jogo não apenas o conteúdo a ser trabalhado mas sobretudo o modo de se trabalhar esse conteúdo, conforme bem lembram Alves \& Ataíde e Melo (2012, p. 128): "Fazer com que alguém aprenda exige não somente o domínio do Saber que se quer fazer aprender, mas também o domínio de uma prática que se operacionaliza nessa ação de 'fazer aprender". Ao longo dos anos, essa questão não se resolveu totalmente, até porque o dinamismo da contemporaneidade exige frequentes revisões dos encaminhamentos que a uma certa altura parecem funcionar, mas que algum tempo depois já não são coerentes. Mesmo assim, alguns equacionamentos podem ser feitos.

Evidentemente, os processos digitais não afetaram só a fotografia, e sim toda a forma de nos relacionar com o mundo, com os outros, ou seja, toda a comunicação compreendida no sentido amplo do termo. No ensejo dessas transformações, o ensino do Jornalismo no Brasil passou também por uma profunda mudança, com a implementação das novas diretrizes curriculares em 2015 que, entre outras novidades, trouxe a instituição do Jornalismo como uma formação autônoma e não mais como uma habilitação da Comunicação. Isso se deu não sem haver nos debates prévios uma intensa polarização em torno da valorização ou das teorias ou das técnicas. Meditsch (2012, p. 31) acusava entre os defensores da permanência do Jornalismo como uma habilitação da Comunicação o "[...]desprezo pela prática profissional como objeto de estudo[...]" que obrigaria os estudantes vocacionados à profissão a escolher:

[...] ou desprezam a teoria ensinada e reafirmam a vocação profissional que os levou à faculdade, desenvolvendo uma forte resistência à atividade teórica, ou abandonam a vocação inicial e tornam-se "comunicadores" sem mercado de trabalho e sem prática, só encontrando colocação na própria universidade como "comunicólogos" (MEDITSCH, 2012, p. 31).

Essa polêmica não se extinguiu, mas os cursos de Jornalismo, pelo menos na forma da lei, a partir de 2013, deixaram de ser uma habilitação da Comunicação. Com isso, foi possível sanar a queixa sobre a diluição dos conteúdos do Jornalismo em conteúdos gerais da Comunicação. Por outro lado, o Fotojornalismo se ressente de um esquecimento dentro dessas novas diretrizes. Como aponta Aquino (2018, p. 1) em seu estudo sobre a ausência de atenção à fotografia nas diretrizes do MEC para os cursos de Jornalismo, há "[...] dificuldade de entendimento do fotojornalismo enquanto área de trabalho do jornalista profissional e da fotografia enquanto linguagem da informação jornalística". Essa ausência foi constatada pela autora desde 1943, quando do primeiro documento que institui oficialmente o Jornalismo entre os cursos de nível superior no Brasil. Apenas as diretrizes de 1962 passariam a considerar o fotojornalismo como uma função exercida pelo jornalista. Se nas diretrizes de 1984 ele figurava de modo explícito, aparentemente um passo atrás foi dado nas diretrizes de 2013, que não lhe fazem citação direta nem indireta. A autora constata que essa ausência 
[...] provocou um efeito cascata nas práticas pedagógicas dos cursos de jornalismo do Brasil. Elas repercutiram em estruturas curriculares com pouca inclusão do fotojornalismo; com a modificação do nome da disciplina de fotojornalismo para outros como: jornalismo fotográfico, introdução à fotografia, linguagem fotográfica, fotografia digital, por exemplo; a não realização de concursos nas universidades públicas para professores com perfil teórico/prático específico na área, sendo as disciplinas de fotografia muitas vezes assumidas por professores que não trabalham diretamente com essa temática, nem em pesquisa nem no fazer fotográfico; ausência da fotografia nos estágios supervisionados obrigatórios; ausência da fotografia como possibilidades de produção nos Trabalhos de Conclusão de Curso e carência de projetos de pesquisa e extensão voltados para a imagem fotográfica (AQUINO, 2018, p. 2).

Assim, ao resolver o problema da dissolução dos conteúdos do Jornalismo na Comunicação, as novas diretrizes curriculares de certa forma reproduziram internamente esse problema no que tange à dissolução da especificidade do fotojornalismo em outras disciplinas. Por outro lado, o princípio geral exposto no artigo 2 das novas diretrizes estabelece que a estrutura do curso de bacharelado deve

propiciar a interação permanente do aluno com fontes, profissionais e públicos do jornalismo, desde o inicio de sua formação, estimulando, desse modo, o aluno a lidar com problemas reais, assumindo responsabilidades crescentes, compatíveis com seu grau de autonomia (MEC/ CNES, 2013).

A partir desse entendimento, abre-se não apenas a possibilidade como também o dever de os cursos de Jornalismo darem espaço ao fotojornalismo como uma disciplina específica, com suas discussões teóricas e suas práticas enraizadas no próprio fazer jornalismo e não como uma aplicação da fotografia ao jornalismo. Foi considerando essa necessidade que se reformulou a disciplina de Fotojornalismo na Universidade Federal do Rio Grande do Sul, como detalharemos adiante.

Passar da prática fotográfica ao ensino da fotografia não é autoevidente, embora haja, segundo Cunha (2004, p. 528), uma crença de que "[...] para ser professor universitário, o importante é o domínio do conhecimento de sua especialidade e das formas acadêmicas de sua produção”. Em busca de pistas para a formatação das aulas, 14 anos atrás, recorri aos meus alfarrábios dos tempos de estudante, na esperança de que os ensinamentos que então recebera me indicassem por onde começar, confirmando a percepção de Kessler (apud CUNHA, 2004, p. 529) da docência como habitus. No entanto, isso não foi possível. É verdade que vários pontos das notas tomadas no meu próprio curso de graduação ainda eram aproveitáveis, mas ao longo dos anos seguintes o foram cada vez menos e hoje os conteúdos que trago para as aulas são decididamente diferentes do que os que meus professores trouxeram. Especulo que, ao contrário do que aconteceu comigo, eles, por sua vez, puderam ensinar o que tinham aprendido de seus próprios professores. As mudanças nas tecnologias da comunicação impactam, claro, toda e qualquer área do conhecimento. No entanto, isso parece se acirrar grandemente na fotografia, seja por sua produção eminentemente técnica, seja pelo grande incremento simbólico que ela recebe a partir do momento em que se torna facilmente transmissível e, mais do que isso, assume um papel protagonista nas comunicações interpessoais e também nas de massa, com todos os riscos trazidos pela ressurreição desse termo banido do campo da Comunicação nos anos 1980.

Em 2006, a disciplina se chamava "Técnicas de fotografia em Jornalismo". Com 2 horas/aula semanais, ela se sucedia a uma disciplina introdutória, "Introdução às técnicas fotográficas", que contava com 4 horas/aula semanais. Seu nome, assim como o da disciplina que lhe era pré-requisito, enfatizava o caráter técnico da fotografia, deixando pensar que a subjetividade seria marginal, desnecessária ou indesejada. A ementa da disciplina tal como a recebi elencava os seguintes itens: Processo fotográfico na perspectiva do jornalismo. Papéis sociais da fotografia jornalística (documentação, testemunho histórico). Direitos autorais. Diferenciação entre as utilizações da fotografia para jornal e revista. Utilização de equipamentos especiais. Editoras jornalísticas e adequação da fotografia. Agências internacionais. 
É de se notar a ausência absoluta de qualquer menção aos novos processos fotográficos na imprensa. A perspectiva jornalística se resumia a uma espécie de aplicação da fotografia, não sendo então o fotojornalismo mais do que um gênero da fotografia. Os papeis sociais atribuídos à fotografia jornalística na ementa da disciplina evidenciam a fé no seu caráter testemunhal. As técnicas fotográficas às quais os alunos eram então iniciados eram as analógicas. Não havia câmeras digitais à disposição. A iniciação em fotografia era feita com câmeras manuais e com filme preto-e-branco. A revelação dos filmes e a ampliação das fotos eram realizadas pelos próprios alunos, ainda na disciplina introdutória. Na disciplina específica de fotojornalismo, continuava-se com a fotografia analógica, com a diferença de se realizar também uma tomada de fotos com filme colorido. No total, duas saídas fotográficas eram realizadas coletivamente, com pauta comum a todos os alunos, que usavam as câmeras da faculdade.

Como se vê, as mídias eletrônicas não eram consideradas na ementa, cuja preocupação voltava-se para a diferenciação entre fotografia para jornal e revista, subentendidos como evidentemente impressos. Parecia haver uma ignorância total a respeito do que se passava no mundo exterior: na vida real, como assinala Gunthert (2015), os portais comerciais na internet começavam a se estagnar enquanto os sites que recebiam conteúdos gerados pelo usuário, como o Flickr, conheciam um incremento significativo em sua frequentação.

No meu planejamento de aulas, ainda tateando não somente sobre o melhor modo de trazer os conteúdos mas também sobre quais seriam esses conteúdos, incluí tópicos de discussão sobre a objetividade no fotojornalismo tentando desprender essa reflexão do fundamento técnico da fotografia. Uma das aulas apresentava uma comparação entre os processos fotográficos analógicos e digitais. O peso que tinham na questão ética a facilidade de alteração das imagens no último caso e a dificuldade da deteç̧ão dessa alteração era relativizado com a apresentação de inúmeros exemplos de manipulação de fotografias históricas obtidas pelo processo analógico. A dificuldade principal era problematizar a objetividade do fotojornalismo, seu caráter de testemunha ocular. Ainda que alvo de numerosas discussões teóricas, a objetividade no jornalismo continua a ser um ponto complexo e que em tempos de ampla circulação de notícias falsas se coloca como justificativa fundamental do jornalismo profissional. $\mathrm{O}$ fato de a fotografia mostrar as cenas apela de modo incontornável ao caráter testemunhal da imagem técnica que, diferente da imagem tradicional, feita pela mão do artista, não mente - ou não deveria mentir. A fotografia digital surgiu com suas inúmeras possibilidades de modificação da imagem originalmente clicada, mostrando-se potencialmente traidora dessa objetividade que tem sido a sustentação moral do jornalismo. Àquela altura, os alunos tinham dificuldade em questionar esse caráter testemunhal da fotografia e compreender que o fotojornalismo também é uma visão de mundo. No máximo, aceitavam que as escolhas técnicas que o fotojornalismo faz traduz uma certa margem de interpretação da realidade: um ângulo contre-plongé poderia figurar um certo empoderamento da pessoa fotografada, por exemplo.

O olhar fotográfico dos alunos ainda estava por se desenvolver, o que era feito muito lentamente. Na maioria das vezes, chegava-se ao final do semestre apenas evitando-se os erros mais óbvios de enquadramento (pessoas com o corpo cortado de modo desagradável, objetos indesejados incluídos no quadro, linha do horizonte torta etc.). Embora as aulas trouxessem fartas referências de fotojornalistas contemporâneos, as práticas eram raras - apenas duas saídas fotográficas no semestre inteiro. Faltava a repetição necessária à confirmação da técnica, que por sua vez é indispensável para que o fotógrafo se libere dessa preocupação para se concentrar no seu tema e na forma de abordá-lo. Uma característica marcante das fotos então produzidas pelos alunos era a preferência pelos enquadramentos horizontais, mesmo de assuntos fortemente verticais, como árvores, edifícios e pessoas em pé: o olhar ainda estava bastante condicionado à disposição horizontal dos nossos próprios olhos, um ao lado do outro.

Um ano mais tarde, a ementa da disciplina teve um tópico acrescentado: "tratamento digital da fotografia em fotojornalismo". As fotografias obtidas analogicamente eram 
digitalizadas usando-se um escâner. Após isso, as imagens eram editadas usando-se o Photoshop. A percepção fotográfica não mudou muito, com os enquadramentos e composições se atendo ainda às regras formais. Num primeiro momento, houve uma piora da qualidade técnica: sabendo que a pós-produção seria feita digitalmente, eram negligenciadas a fotometragem e a focalização. A grande surpresa dos alunos acontecia quando o Photoshop não conseguia resolver a luz estourada, a subexposição e os abundantes desfoques. De certa forma, ao mostrar que a fotografia digital não tem poderes infinitos, isso ajudou a levar um pouco adiante a discussão sobre a veracidade fotográfica.

O ano de 2009 marca a implementação de novos currículos nas três habilitações da graduação em Comunicação na Universidade Federal do Rio Grande do Sul. A disciplina passa a se chamar então simplesmente "Fotojornalismo", mas mantém a carga horária de apenas 2 horas/aula semanais. A ementa então reza: "O perfil e a formação profissional do fotojornalista. Fotografia e linguagem jornalística. A prática da reportagem fotográfica. Análise das diferenças de linguagem em fotojornalismo e seus modos de realização nos diversos veículos de comunicação.” A principal mudança me parece residir no deslocamento de uma ideia de fotografia aplicada ao jornalismo para uma fotografia jornalística propriamente dita, que porta uma linguagem própria, diferenciada internamente e não em relação à fotografia em geral. Isso abre espaço para a não restrição dos papeis sociais da fotografia jornalística à documentação e ao testemunho histórico anteriormente registrados na ementa.

As aulas agora passaram a dedicar um tópico inteiro ao que era então denominado como o impacto da fotografia digital sobre o fotojornalismo. As discussões ainda são bastante atreladas à fragilização da veracidade fotojornalística diante das possibilidades manipulatórias trazidas pelos pixeis. A produção de fotos continua a ser basicamente analógica: os alunos fotografam com uma câmera Nikon N80, revelam o filme, ampliam as fotos em papel e digitalizam-nas. As saídas fotográficas passam a ser em horário extra-classe, de modo que as pautas podem ser individualizadas. $\mathrm{O}$ equipamento é emprestado à maioria dos alunos, mas alguns já têm câmeras digitais compactas e podem utilizá-las nos trabalhos. Poder-se-ia dizer que, do ponto de vista estritamente técnico, estávamos cerca de uma década atrasados em relação ao que se fazia nas redações de jornal, ainda na etapa que Silva Júnior (2012) chamou de pré-adaptativa na transição do fotojornalismo analógico para o digital. Segundo o autor, nessa etapa, datada do início dos anos 1990, a produção é orientada para veículos impressos e a fotografia analógica é traduzida para a digital por meio de escâners. Silva Júnior sublinha que os fotojornalistas então "não possuíam a polivalência do domínio tecnológico, restringindo-se a atividades do entorno fotográfico, como revelar, ampliar e editar o material visualmente e não necessariamente a predominância de esforços cooperativos para a produção de materiais visuais de maior complexidade" (SILVA JÚNIOR, 2012, p. 35). Seriam necessário aguardar até 2018 para que esses esforços cooperativos participassem concretamente da disciplina de Fotojornalismo na UFRGS.

\section{Captura digital}

Em 2011, a faculdade adquire e disponibiliza aos alunos câmeras reflex digitais. Foram seis unidades da Nikon D 3000; os alunos rodiziavam seu uso para dar conta dos trabalhos da disciplina. Chega-se assim ao emparelhamento entre as técnicas aprendidas na universidade e as utilizadas no mercado, pois esse último, apesar de ter saído na frente, não continuou desenvolvendo as consequências da nova tecnologia. Nota-se que o básico da fotografia continua como antes, refletindo o que se passava nas práticas. Gunthert (2015) observa que, apesar da facilidade de copiar e/ ou manipular fotos e mesmo de transmiti-las, houve continuidade nas suas formas e usos pelos 20 anos de transição do analógico ao digital. É possível afirmar que nesse momento atingimos a segunda etapa dessa transição indicada por Silva Júnior, pois os filmes e a fotografia em papel não eram mais utitlizados na disciplina específica de Fotojornalismo (embora ainda utilizados na disciplina geral de Introdução à 
${ }^{3}$ Conforme matéria então publicada no Correio Braziliense em 01/01/2011 Disponivel em: https:// www.correiobraziliense. com.br/app/noticia/economia/2011/01/01/internas_economia,230322/ em-20-anos-brasil-deixa-a-era-do-telefone-fixo-para-as-videochamadas.shtml. Acesso em: 15 jun. 2019.

${ }^{4}$ Conforme http://g1.globo. com/tecnologia/noticia/2012/04/entenda-curta-historia-do-instagram-comprado-pelo-facebook. html. Acesso em: 15 jun.

2019.

${ }^{5}$ Conforme https://canaltech. com.br/redes-sociais/Facebook-apresentou-crescimento-de-460-no-Brasil-em-menos-de-dois-anos/. Acesso em: 15 jun. 2019.
Fotografia), a exemplo do que descreve o autor sobre essa fase por ele chamada de "adaptativa": o fluxo de trabalho digital já está instaurado e o fotógrafo, "[...] além de dominar os dispositivos do entorno fotográfico, [têm] competência com sistemas de ordem informacional, como, por exemplo, a ingestão, transmissão, catalogação, tratamento e armazenamento de imagens" ( SILVA JÚNIOR, 2012, p. 36).

A grande mudança veio com a possibilidade de compartilhamento quase imediato das fotografias nas redes sociais através dos dispositivos móveis. Em 2011, comemoraram-se os 20 anos da telefonia móvel no Brasil. ${ }^{3} \mathrm{O}$ Instagram já existia há um ano, tendo chegado a 1 milhão de usuários com apenas três meses de mercado e, em 2011, seria considerado o aplicativo do ano pela Apple. ${ }^{4}$ O Facebook também já estava instalado no Brasil, com 12 milhões de usuários. Dois anos mais tarde, já teria crescido $460 \% .^{5}$ A integração de dispositivos fotográficos aos telefones celulares já era uma realidade desde o início dos anos 2000, mas foram os smartphones que trouxeram uma mudança profunda na cultura visual em virtude da possibilidade de publicar ou enviar para amigos quase imediatamente as imagens produzidas. A partir de então, tirar uma foto não é mais suficiente; é necessário compartilhá-la. Gunthert (2015) vai mais longe e mostra como a associação entre as redes sociais e os dispositivos fotográficos móveis modifica radicalmente os usos da fotografia: diferente de plataformas como o Flickr, em que o objetivo também era compartilhar e comentar fotografias, as redes sociais, com o Facebook à frente (ainda nesse ano de 2020) não é um espaço de discussão especializado: "As imagens não são prioritariamente mobilizadas por suas qualidades estéticas, mas porque eles documentam a vida, participam do jogo de autorrepresentação e servem a fins referenciais" (GUNTHERT, 2015, p. 139). Trata-se, no dizer do autor, de uma revolução da desespecialização. Em 2017, Silva Jr. (2012, p. 159) afirma o mesmo de outro modo:

Se for clicada, mas não circulada, a imagem produzida carece de uma existência completa, pois não compartilha, não se alinha, com os valores pertença de produção de conteúdos com que convive.na atualidade, como redes sociais e blogs, por exemplo (SILVA JUNIOR, 2012, p.159).

Fotografar torna-se, com os smartphones conectados a redes sociais, um ato cotidiano, repetido várias vezes ao dia. Parece claro que o estímulo para se apertar o botão e registrar a imagem se amplifica consideravelmente com a possibilidade de partilhar o resultado ao ponto mesmo de a fotografia perder o sentido se não puder ser publicada nas redes.

Com o fotografar tornando-se rotina, muda o olhar fotográfico. Em 2012, percebo que a dificuldade não é mais lembrar os estudantes da possibilidade de se segurar a câmera na vertical e sim na horizontal. Fotografar é agora um hábito, mas um hábito ligado aos smartphones, aparelhos retangulares pensados para serem segurados na posição vertical para quase todos os usos, pois seu desenho assim se acomoda melhor à mão. Embora seja possível segurá-los na posição horizontal para fazer fotos ou vídeos, os usuários tendem a continuar posicionando-os na vertical nesses momentos. Ao empunharem a câmera fotográfica pela primeira vez, guiados pelo hábito do olhar verticalizado, os estudantes têm a tendência, nesse momento inicial de boom do uso dos aparelhos celulares, a adotar enquadramentos verticais, buscando reproduzir o enquadramento que já usam habitualmente. Isso me parece grandemente esclarecedor do papel que o repertório visual de um fotógrafo exerce sobre sua produção: fotografamos o que já conhecemos.

Foi a partir de 2014 que ficou bastante evidente a autonomia dos estudantes que chegavam à disciplina no que concerne à intuição da composição e mesmo da noticiabilidade. Não mais parece necessário enfatizar longamente as regras clássicas de composição, colocá-las em discussão e relativizar sua necessidade. A iniciação continua a ser feita na disciplina introdutória a partir da fotografia analógica e com uma experiência de tomada de fotos com câmera DSLR, sem se abordar, ainda, a pós-produção digital, que a esse tempo já está bastante difundida no mercado com editores de imagem pensados para a fotografia em Comunicação, como o Lightroom, 
já que o Photoshop se configura mais como um pesado programa de design gráfico. A disciplina de fotojornalismo definitivamente não cabe mais nas duas horas semanais de aula. Sente-se a pressão do pouco tempo para aprofundar reflexivamente as questões específicas de um fotojornalismo que se transforma rapidamente - o webjornalismo com todas as suas consequências para a fotografia, fazendo convergir em uma só plataforma diversas mídias, está em pleno funcionamento nesses anos. O fluxo de trabalho digital é abordado muito rapidamente, no sentido de dar indicações sobre onde encontrar mais informações. No âmbito das discussões sobre as Diretrizes Curriculares Nacionais para os cursos de graduação em Jornalismo, começa-se a essas alturas a gestar um novo formato para a disciplina de fotojornalismo.

Em 2015, 25 câmeras DSLR (Nikon D 7000) foram adquiridas e os estudantes passaram a trabalhar com elas já na disciplina introdutória de fotografia, após terem realizado trabalhos em câmeras SLR com filme preto-e-branco. A ênfase técnica na disciplina introdutória continuava a ser sobre a fotografia analógica, enquanto na disciplina específica de fotojornalismo usavam-se apenas as câmeras DSLR. No mesmo ano de 2015, animados pela ampliação da disponibilidade dos equipamentos digitais, criamos uma conta no Instagram para publicar os trabalhos realizados pelos estudantes. No entanto, naquele ano apenas uma fotorreportagem foi publicada, mostrando o metrô da cidade.

\section{Figura 1 - Transporte público foi tema da primeira fotorreportagem publica- da na conta Instagram da disciplina Fotojornalismo}
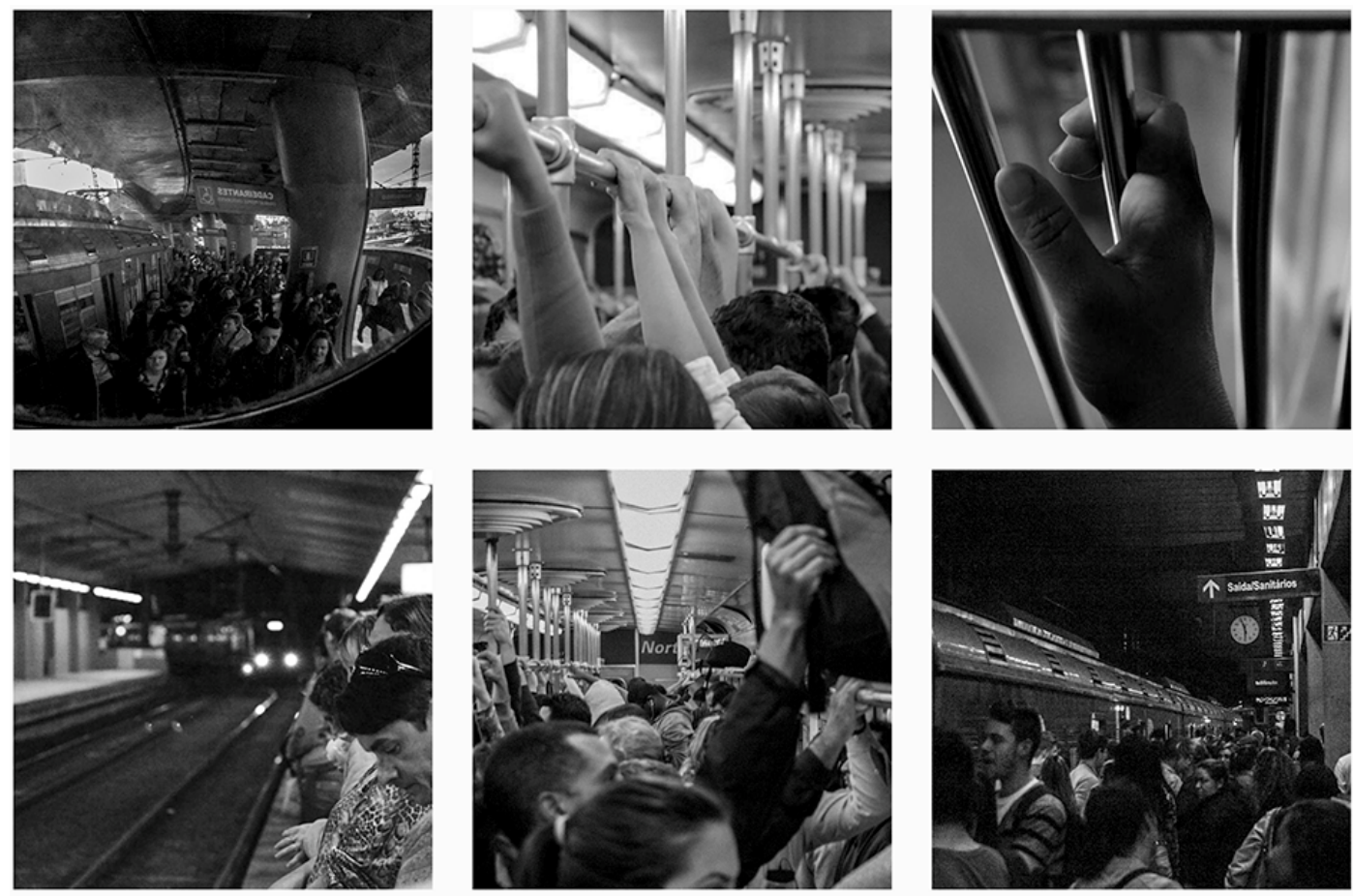

Foto: Caleu Nunes, Henrique Moretto e Letícia Paludo, 2015. Fonte: @fotojornalismoufrgs

No ano seguinte, 2016, nada foi publicado nessa conta. As produções continuavam restritas à visualização e leitura crítica em sala de aula. Em parte, isso se deveu à dificuldade de se adotarem decididamente os dispositivos fotográficos embutidos nos smartphones no trabalho da disciplina. As dificuldades eram de ordem material - muitos alunos ainda não dispunham de um smartphone àquela altura -, mas sobretudo de ordem conceitual: é necessário admitir que as novas tecnologias em fotografia eram vistas como amadoras e que de certa forma ainda grassava a ideia do dever de se trazer para a sala de aula a fotografia profissional, a compreensão dos processos técnicos embutidos no ato fotográfico como condição para se produzir reflexivamente e não mecanicamente. E os processos técnicos, naturalmente, são muito mais visíveis nas câmeras SLR do que nos smartphones e mesmo do que nas 
câmeras DSLR: enquanto é possível abrir a tampa traseira de uma SLR e acionar o botão do obturador observando-se o que acontece - a cortina que se levanta, sendo seu movimento observável ou não de acordo com a velocidade escolhida, o espelho que recua, o diafragma que se fecha até o ponto previamente definido... - as câmeras DSLR são totalmente fechadas.

Em 2017, a conta da disciplina no Instagram começa a ser alimentada regularmente. As fotografias são obtidas com as novas DSLR, descarregadas num computador conectado à internet e então publicadas.

\section{Produção com dispositivos móveis}

O novo currículo do agora curso de graduação em Jornalismo é implementado a partir de 2018 na UFRGS. Como já referido, o modelo anterior estava sob as diretrizes de 2009, quando o Jornalismo ainda era uma habilitação de Comunicação Social. De fato, a maior ênfase então dada no currículo à disciplina de Introdução à Fotografia, que tinha o dobro da carga horária de Fotojornalismo, dispersava os conteúdos específicos de fotojornalismo em conteúdos gerais da Comunicação. Mesmo que o professor desejasse, era inviável abordar as questões específicas de Fotojornalismo no escasso tempo que a disciplina dispunha. Por seu forte apelo técnico, talvez se pudesse pensar que a fotografia possa ser ensinada à parte de suas "aplicações", deixando-se para uma instância separada a reflexão sobre a ética em fotojornalismo, sobre as rotinas fotojornalísticas, sobre técnicas que são predominantemente usadas em fotojornalismo. Sentia-se sobretudo a falta de um adensamento das práticas narrativas fotojornalísticas, que seguem uma sintaxe própria. Se em alguns casos pode-se afirmar que uma fotografia é apenas uma fotografia e será publicitária, artística ou fotojornalística dependendo do contexto de sua veiculação, não há como ignorar o fato de que as imagens que servem à responsabilidade social do jornalismo não podem ser produzidas de modo genérico para depois serem encaixadas nas necessidades do jornalismo. Compreendendo-se a fotografia muito além do instante em que se aciona o obturador, fica clara a especificidade do fazer fotojornalístico: o antes e o depois do "instante decisivo" em fotojornalismo diferem completamente do antes e depois do "instante decisivo" em publicidade, em relações públicas, em fotografia de casamento, em fotografia amadora etc.

A partir da implementação das novas diretrizes curriculares de 2013, em 2018 Fotojornalismo passa a contar não mais com 2 horas/aula semanais e sim com 8. A necessidade de se fazer uma iniciação digital mais precoce levou a disciplina de fotojornalismo a se descolar da disciplina introdutória, ainda dedicada grandemente aos processos fotográficos analógicos e ao trabalho teórico sobre a fotografia em geral. As disciplinas de fotografia agora se chamam Fotojornalismo I (obrigatória do terceiro semestre) e Fotojornalismo II (obrigatória do quarto semestre). Com a nova formatação, torna-se possível trabalhar conteúdos fotojornalísticos desde o primeiro momento, havendo espaço para o desenvolvimento da narrativa fotográfica, da compreensão e reflexão crítica sobre a sintaxe fotojornalística. Ou seja, o fotojornalismo não é abordado como uma aplicação fotográfica e sim realmente como um disciplina. As técnicas e a história são trazidas concomitantemente às práticas fotojornalísticas. O smartphone é definitivamente integrado às aulas, com os alunos usando-os normalmente, sem se descurar o aprendizado dos processos fotográficos com as câmeras DSLR. Estamos em plena terceira fase da transição do analógico para o digital, segundo a classificação de Silva Júnior (2012): é a etapa por ele chamada de convergente, definida tanto por aspectos gerenciais e tecnológicos (fusão de empresas, dispositivos multitarefas, produção de um mesmo conteúdo para vários meios etc.) quanto pelo aspecto cultural, no qual, com Jenkins (2008) o autor vislumbra que "[...] a cadeia de produção é concebida como um processo que afeta tanto o modo de produção do conteúdo como o seu consequente consumo" (SILVA JÚNIOR, 2012, p. 36). 
Observando a absoluta familiaridade dos estudantes com a obtenção e publicação de fotografias no seu cotidiano, proponho, já no primeiro dia de aula de Fotojornalismo I, uma tarefa avaliativa: no espaço de 45 minutos os estudantes devem apurar uma pauta, fotografar, elaborar legenda e publicar na conta do Instagram a fotonotícia. A apuração é feita na própria faculdade e imediações; a obtenção da fotografia é feita com os smartphones individuais - agora já praticamente todos os estudantes têm o seu. Em que pesem alguns deslizes de enquadramento, são notáveis os bons resultados da tarefa. A familiaridade com a fotografia sem dúvida enseja um olhar que mais rapidamente encontra o seu tema e intuitivamente procura destacá-lo do fundo. Escrever a legenda também não se apresenta como um grande problema, estando esses estudantes já no terceiro semestre de um curso que conta com oito no total.

Figura 2 - A estudante Eduarda Romagna confecciona cartaz para as calouradas. Fotonotícia produzida no primeiro dia de aula da disciplina de Fotojornalismo I

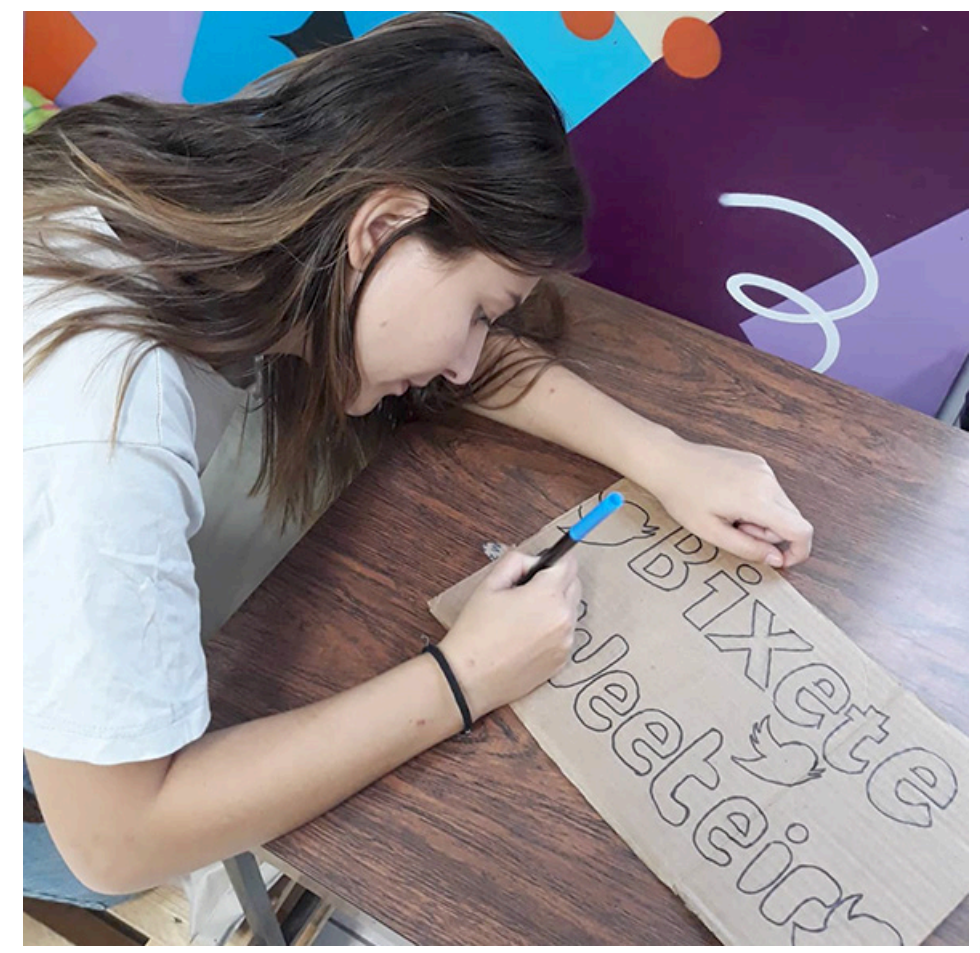

Foto: Rafaela Pereira, 2019. @fotojornalismoufrgs

Por outro lado, os conteúdos técnicos da fotografia manual parecem oferecer tanto mistério quanto há 13 anos, quando os estudantes ainda não praticavam cotidianamente a fotografia. São necessários vários cliques equivocados e muitas repetições das regras que regem o controle da luz que atinge o sensor para que a informação se torne naturalmente presente no espírito e finalmente eles consigam se concentrar sobre o assunto - isso só é alcançado ao final da disciplina da Fotojornalismo II.

Evidentemente, entra nessa conta o fato de serem relativamente escassas as oportunidades em que eles têm acesso à câmera DSLR: inicialmente, em Fotojornalismo I, há uma aula de contato com a câmera, quando são apresentados e experimentados os controles manuais. Na semana seguinte, é feita uma saída fotográfica coletiva a locais da cidade que ofereçam uma variedade de motivos, desde humanos até arquitetônicos e naturais, como o jardim botânico, alguns parques ou mesmo o próprio campus, para obtenção de fotos à luz do dia. Os estudantes cumprem então uma série de tarefas pré-determinadas, exercitando o uso de velocidades (movimento escorrido, movimento congelado) e aberturas diferentes (alta e baixa profundidade de campo), a criação de perspectivas lineares e por redução de escala, a fotometria em contraluz e de assuntos iluminados desigualmente, além de alguns aspectos clássicos da composição e enquadramento (regra dos terços, fora de campo, plongé, contre-plongé etc.). Os resultados desses exercícios são co- 
mentados criticamente na aula seguinte. Algumas semanas mais tarde, depois de algumas aulas em que se abordam aspectos teórico-filosóficos, uma nova aula prática é ministrada apresentando-se os controles automáticos das câmeras DSLR, os quais são na mesma ocasião experimentados pelos estudantes na obtenção livre de fotografias nas imediações da faculdade. Finalmente, ainda em Fotojornalismo I, os estudantes têm, no terço final do semestre, a possibilidade de retirar emprestadas as câmeras por uma semana para a realização das fotorreportagens com pauta livre. Em Fotojornalismo II, não são realizadas saídas coletivas, mas câmeras são igualmente emprestadas aos estudantes para cumprir as duas atividades práticas (uma fotorreportagem e um ensaio) em horário extraclasse.

O desenvolvimento de um olhar fotojornalístico sobre os assuntos é trabalhado de duas formas: através da leitura crítica das fotografias produzidas e através da reflexão teórica sobre esse olhar. Assim, por exemplo, é necessário chamar a atenção dos jovens fotógrafos para o fato de que devem se colocar nos contextos como quem os reporta e não simplesmente como quem participa deles. A situação clássica ocorre na cobertura de palestras, quando eles ainda têm a tendência de ocupar um lugar junto ao público e captar de lá as imagens, mostrando muitas pessoas de costas e os palestrantes diminutamente representados no último plano da imagem. Também em manifestações populares é esse o enquadramento que mais ocorre.

Ao mesmo tempo em que se estimula uma maior assertividade na cobertura, pela compreensão do papel do fotojornalista como mediador social e que não deve, pois, se constranger por se posicionar à frente das cenas, por talvez perturbar momentaneamente o evento com os cliques e flashes, questiona-se o ângulo de tomada que é usado para causar o efeito de realidade no fotojornalismo em nome da objetividade, a regra velada de que a cena deve ser enquadrada de tal modo que ao se olhar para a sua foto tem-se a impressão de olhar para a própria cena, apagando-se o ponto de vista do fotógrafo. Concomitantemente às discussões sobre as relações do fotojornalismo com a realidade de que ele trata, embasadas em textos clássicos (MACHADO, 1984; DUBOIS, 1983) estimula-se o uso não só de recursos que quebram o efeito de realismo - por exemplo, a inclusão de superfícies espelhadas no enquadramento que reenviam para as cenas que não foram enquadradas, o uso de molduras naturais que chamam a atenção para a posição muitas vezes atocaiada do fotógrafo - como também a apropriação do ponto de vista de terceiros como seu próprio, através da realização de fotorreportagens em coletivos: grupos de três ou até quatro estudantes constroem uma pauta, acordam os modos de cobri-la e executam-na em temporalidades e espacialidades coincidentes e diferentes. Assim, ora todos se encontram no mesmo local, cobrindo a mesma coisa, e disso emergem variados pontos de vista sobre essa mesma situação, ora cada um ruma para uma espacialidade diferente da pauta e cobre-a a seu modo. A edição das fotografias é feita conjuntamente pelo grupo, sem obrigatoriedade de fornecer no trabalho final, por exemplo, um certo número de fotos tiradas por cada integrante. Exercita-se a autoria coletiva, compreendendo-se que o fotojornalismo não começa e termina no clique. 
Figura 3 - Fotorreportagem coletiva sobre a presença negra na universidade pública.

Da esquerda para a direita, do alto para baixo, Caroline Inês Silva dos Santos, Brenda Luíza Ferreira Vidal, Gabriela Carneiro Gonçalves, Karolaine Leão, Lyz Ramos, Gabriela Gil (estudantes), Sandra de Deus (professora), Kênia Roberta da Rosa Fialho e Hillary Marniery (estudantes).
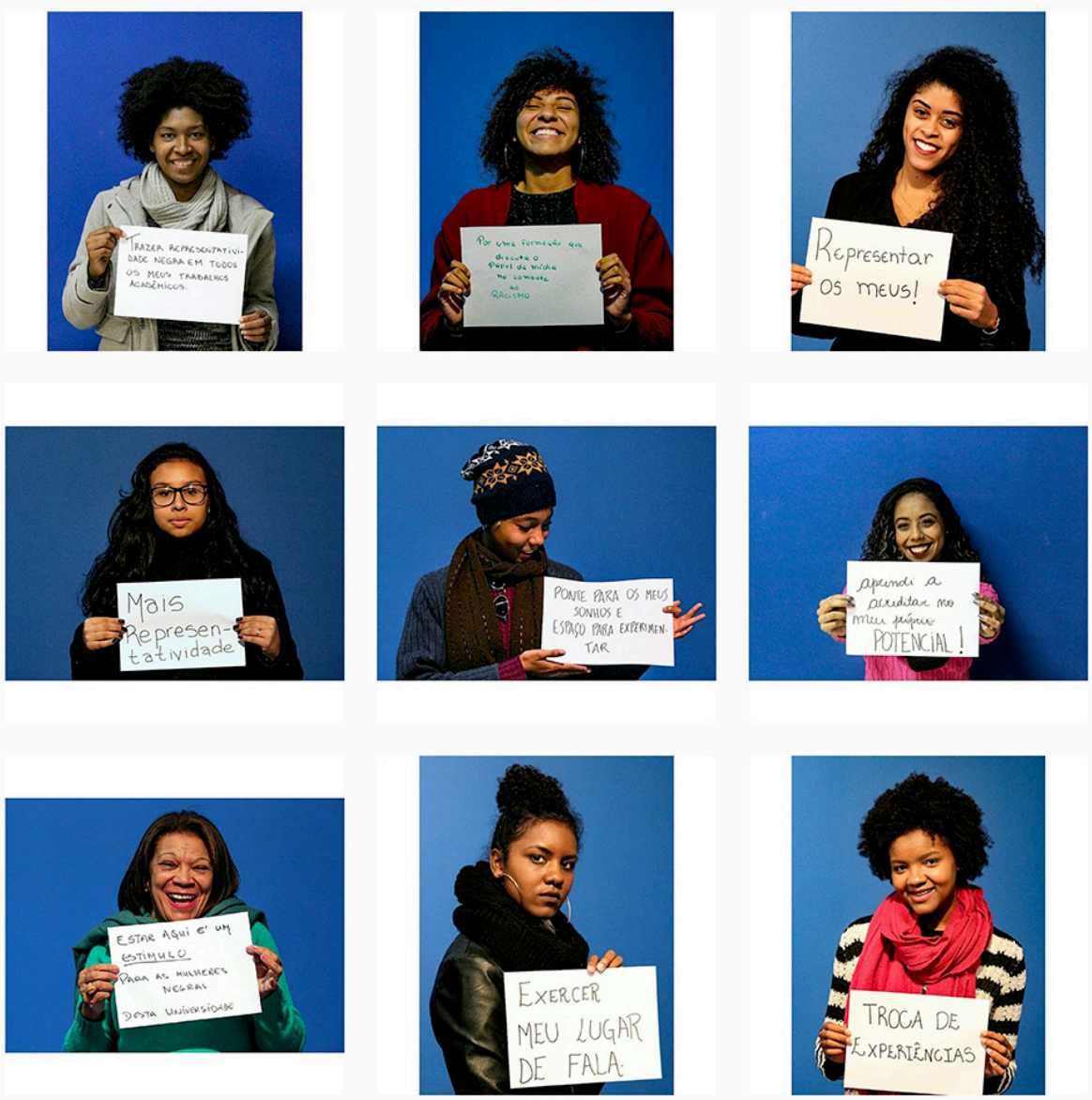

Fotos: Andrielle Prates, Raíssa De Avila e Vítor Prado, 2018. @fotojornalismoufrgs

Em Fotojornalismo II, tendo já sido bastante exercitados os aspectos narrativos da fotorreportagem, avança-se sobre três outros aspectos, todos eles aprofundando a reflexão sobre as subjetividades na profissão: o uso de luz controlada, o trabalho em equipe com repórteres de texto e o desenvolvimento de uma linguagem pessoal através do ensaio.

O uso de luz controlada (flashes dedicados, no caso) é exercitado através do trabalho com pastiche, com a imitação de estilos de retrato, especificamente. A noção da autoria coletiva continua e se reforça aqui, pois o trabalho em estúdio, mesmo com o uso de flashes dedicados, é altamente dependente da equipe, já que são múltiplas as tarefas, desde a produção do retratado até a organização dos equipamentos do estúdio (fundos, modificadores de luz, tripés etc.). Organizados em grupos, os estudantes escolhem um retrato já publicado em qualquer mídia como referência para o retrato que farão. A simples imitação técnica da foto que serve de referência, no entanto, não é o objetivo principal. Sob esse ponto de vista, exige-se apenas que a foto produzida lembre imediatamente a foto referenciada (para os que a conhecem, claro). A complexidade da tarefa recai sobre a escolha da pessoa retratada: é partir do personagem da reportagem hipotética que se elege a foto que servirá de referência. Reflete-se, aqui, sobre o quanto do retratado temos de saber ou compreender para buscar a expressão de sua personalidade na foto que realizaremos. A conexão humana, sob esse aspecto, é fundamental. O retratado não é um modelo que se adapta docilmente ao que o fotógrafo deseja do mesmo modo que será impossível capturar na foto apenas a essência do retratado. Esse jogo, que deve ser resolvido na intersubjetividade se complica e se 
complexifica quando entra em cena a fotografia de referência: há a imitação de um estilo para que se traduzam as subjetividades do grupo fotógrafo e do retratado.

O trabalho em equipe com o repórter de texto é realizado em parceria com uma disciplina do final do curso, Jornalismo Impresso, cujo objetivo material é a publicação da revista-laboratório do curso. Até o momento, foram realizadas quatro edições da revista com a colaboração dos alunos de Fotojornalismo II. Alguns aspectos processuais foram se evidenciando ao longo desses semestres e que ainda aguardam por equacionamentos e encaminhamentos. O primeiro desses aspectos poderia ser considerado quase banal: a relação do fotógrafo com o repórter de texto. A revista trabalha com edições temáticas. Dentro do tema geral acordado pela turma de Jornalismo Impresso, cada estudante dessa disciplina elabora sua própria pauta. O conjunto das pautas é então repassado para Fotojornalismo II, cujos estudantes escolhem o que vão cobrir. As dificuldades vão, aí, desde a simples comunicação entre o fotógrafo e o repórter de texto até o entendimento sobre a melhor forma de se traduzir imageticamente a pauta em questão. Tentamos melhorar essa comunicação com a realização de reuniões de pauta conjuntas entre as turmas, sincronizando os dias das aulas das duas disciplinas. Isso resolveu os problemas mais óbvios de organização, mas restou a questão de fundo: enquanto os alunos de Fotojornalismo II devem realizar uma fotorreportagem, os alunos de Jornalismo Impresso precisam de fotos para ilustrar as matérias que estão escrevendo. Um dilema se instaura para os jovens fotógrafos: a imagem vai ilustrar o texto ou vai contar uma história própria?

A priorização do texto sobre a foto vem se amenizando consideravelmente com o jornalismo convergente, já que a rolagem rápida das telas por um usuário com atenção distraída exige o uso farto de imagens. A fotografia é recebida de modo quase abdutivo pelo usuário, sincrônico mesmo, o "tudo é dado de uma só vez" de Dubois mais do que presente nesse momento, enquanto o texto exige a diacronia, o percorrer das linhas, a parada sobre a tela. No entanto, no jornalismo impresso, historicamente a imagem ilustra o texto. Essa diferença de objetivos que os estudantes de Fotojornalismo II e de Jornalismo Impresso precisam alcançar com uma mesma pauta pede ainda um trabalho pedagógico para que os resultados da atividade sejam mais satisfatórios. Isso passa, acredito, pela definição da pauta, já que a imersão em uma fotorreportagem exige um envolvimento, um comprometimento com o assunto abordado que talvez não seja alcançado quando essa pauta é construída unilateralmente.

A sequência das duas disciplinas é encerrada com a produção, em Fotojornalismo II, de um ensaio. Essa tarefa é obrigatoriamente individual. O tema do ensaio de cada um é apresentado e discutido já em uma das aulas iniciais do semestre. Os estudantes são encorajados a iniciar imediatamente a obtenção de fotos, sempre perseguindo seu tema, e a apresentar os resultados que estão alcançando ao longo das aulas, informalmente. Em geral, ao final da aula, alguns minutos são reservados para essas rápidas orientações individuais em que, mais do que se detectarem problemas técnicos, busca-se perceber o olhar pessoal do fotógrafo, o qual muitas vezes é inconsciente para ele mesmo, e motiva-se o aprofundamento, a radicalização desse olhar, como no trabalho apresentado pela discente Rafaela Frison (figura 4), em que os enquadramentos mostram apenas chão e pés. 


\section{Figura 4 - ensaio fotográfico sobre pés de esportistas desenvolvido em Fotojornalismo II}
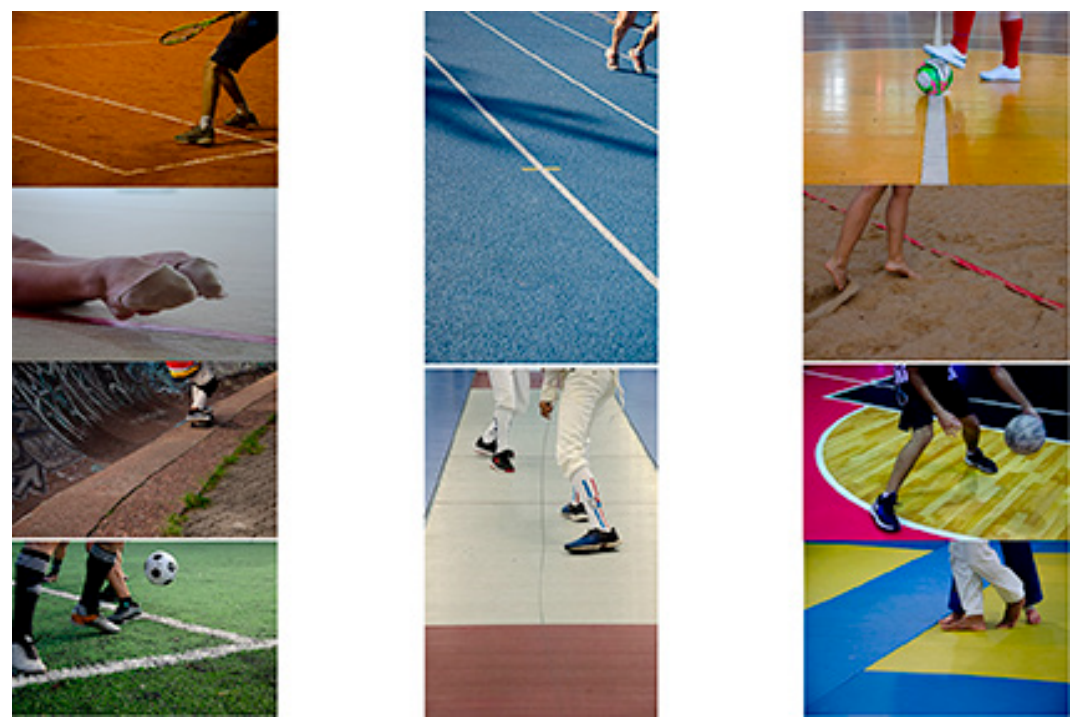

Foto: Rafaela Frison, Por onde pisam os atletas?, 2019.

Sendo um trabalho autoral, o ensaio depende grandemente do processo de autoconhecimento de cada um. Descobrir não apenas o que se gosta de fotografar, mas sobretudo como se gosta de fotografar faz parte de uma descoberta mais ampla de si mesmo. Dada a faixa etária dos estudantes (cerca de 18 anos), a maioria deles ainda está nas primícias desse autoconhecimento. Enquanto a escolha do tema não parece oferecer dificuldades - cada um tem já suas paixões -, o recorte já apresenta mais obstáculos. Quando a indefinição desse recorte chega a um ponto paralisante, o aluno não traz fotos no decorrer do semestre, ou traz imagens muito genéricas, que não evidenciam seu ponto de vista. Nesses casos, é sugerido um caminho técnico específico, com o uso de um dado elemento (contraluz, subexposição, baixa profundidade de campo combinada com plano detalhe etc.) em uma série de fotos a fim de se construir uma coerência interna na abordagem do tema. Ao cabo desse exercício, o estudante geralmente consegue definir melhor o que realmente deseja expressar sobre o tema escolhido através de suas fotos e se sente mais independente para buscar a materialização dessa expressão.

Nesse momento, envidam-se esforços para que as práticas pedagógicas estimulem a criatividade. Além de instigar o debate sobre os impasses que a confrontação da teoria da fotografia com as práticas fotojornalísticas traz, busca-se estimular a expressão da personalidade dos estudantes, não só com abertura a ideias divergentes como também através do incentivo à expressão imagética dessas ideias através do ensaio fotojornalístico. A intenção é, nas palavras de Meditsch (2012, p. 35), reencontrar "[...] o elo perdido entre teoria e técnica" de modo que "[...] as técnicas [passem] a ser entendidas, dominadas e produzidas enquanto tecnologias".

\section{Prospecções}

Ao longo desses anos de transição do processo fotográfico analógico para o digital e de consolidação desse último, mais uma vez se confirma que as mudanças tecnológicas não forçosamente acarretam mudanças de visão de mundo - talvez, seja necessário um tempo bem mais longo de uso das novas tecnologias para que elas tragam reconfigurações epistemológicas. Dizer a verdade ainda parece um pressuposto da fotografia, mesmo com toda a consciência sobre a maleabilidade que a manipulação da imagem no nível microscópico do pixel possibilita. $\mathrm{O}$ jogo do falso e verdadeiro pertence a um regime dualista do imaginário que teve sua fertilidade posta à prova durante os milênios de desenvolvimento da razão ocidental em todos os domínios, começando pela filosofia, passando pela concepção mecanicista da natureza e desembocando na técnica. 
No entanto, esse não é o único jogo possível, posto que o imaginário também se alimenta de outras lógicas, como a da fusão - que, no limite, é um paroxismo da lógica dualista e vice-versa - e a da coincidência de opostos.

O processo digital no fotojornalismo enseja a retomada dessa discussão sobre a verdade jornalística que é, em suma, uma reflexão sobre a verdade em geral. A lógica da coincidência de opostos ou do terceiro incluído provavelmente é a melhor resposta para se equacionarem os problemas colocados pelo dualismo que apenas funciona quando é possível se introduzirem distinções claras. Não é o caso da verdade jornalística, eivada por múltiplas forças muitas vezes divergentes entre as quais a subjetividade do jornalista não é a menor. Se os estudantes de fotojornalismo chegam ao curso já com um olhar treinado para a fotografia, isso se deve, sem dúvida, à inerência da cultura da imagem em suas vidas, diferente das gerações anteriores. Enquanto professores, nossa responsabilidade intelectual e ética se amplia com essa nova condição, impondo-se a necessidade de renovação das didáticas. Novas formas de promover a iniciação técnica são requeridas, formas essas que levem em conta o que esse estudante já sabe - e essa parcela do conhecer técnico aumenta a cada ano. Utilizar esse saber prévio como recurso sensibilizador para as questões filosóficas é o que poderá fazer com que a iniciação em fotojornalismo que propiciamos faça diferença não só para as futuras práticas profissionais dos estudantes, mas também para sua própria vida.

\section{Referências}

ALVES, José Matias \& ATAÍDE E MELO, Ana Luísa C. Fernandes de. Contributos para a compreensão das práticas pedagógicas no ensino superior - um estudo exploratório sobre a autoperceção dos docentes. Revista Portuguesa de Investigação Educacional, v. 12, 2012, p. 125-149.

AQUINO, Agda Patrícia Pontes de. Jornalismo sem foco: a ausência da fotografia nas novas diretrizes do Mec para os cursos de jornalismo. ANAIS do XXIV Encontro de Pesquisa Educacional do Nordeste - Reunião Cientifica Regional da ANPEd. João Pessoa, Universidade Federal da Paraíba, 2018.

CONSELHO NACIONAL DE EDUCAÇÃO. Diretrizes Curriculares Nacionais para o curso de graduação em Jornalismo. Ministério da Educação, 2013. Disponível em: http://portal.mec.gov.br/index.php?option=com_docman\&view=download\&alias=14242-rces001-13\&category_slug=setembro-2013-pdf\&Itemid=30192. Acesso em: 17 set. 2020.

CUNHA, Maria Isabel da. Diferentes olhares sobre as práticas pedagógicas no Ensino Superior: a docência e sua formação. Educação. Porto Alegre - RS, ano XXVII, n. 3 (54), p. 525-536, Set./Dez. 2004

DUBOIS, Philippe. O ato fotográfico. Campinas: Papirus, 1993.

FATORELLI, Antonio. Fotografia e modernidade. In: SAMAIN, Etienne (Org.). O Fotográfico. São Paulo: Hucitec, 2005.

FONTCUBERTA, Joan. O beijo de Judas. Barcelona: Editorial Gustavo Gili, 2010. Edição do Kindle.

GUNTHERT, André. L'image partagée. La photographie numérique. Paris: Éditions Textuel, 2015. 
JENKINS, Henry. Cultura da convergência. São Paulo: Aleph, 2008.

MACHADO, Arlindo. A ilusão especular: introdução à fotografia. São Paulo: Funarte; Brasiliense, 1984.

MEDITSCH, E. A formação para a praxis profissional do jornalista: uma experiência brasileira inspirada em Paulo Freire. Comunicação e Sociedade, v. 5, p. 25, 21 dez. 2012.

MITCHELL, William J. The reconfigured eye: visual truth in the post-photographic era. Cambridge: MIT Press, 1992.

SILVA Jr., José Afonso da. Cinco hipóteses sobre o fotojornalismo em cenários de convergência. Discursos Fotográficos, Londrina, v. 8, n. 12, p. 31-52, jan./jun. 2012 | DOI 10.5433/1984-7939.2012v8n12p31.

SILVA Jr., José Afonso da. O segundo clique da fotografia. Entre o registro e o compartilhamento. Discursos Fotográficos, Londrina, v. 13, n. 22, p. 147-168, jan./jul. 2017 | DOI10.5433/1984-7939.2017v13n22p147.

SOUSA, Jorge Pedro. Uma história crítica do fotojornalismo ocidental. Chapecó: Argos. Florianópolis: Letras Contemporâneas, 2004. 